\title{
Ensuring education for all in India: Highlighting the obstacles
}

International Institute for Population Sciences (IIPS)

Population Council

Follow this and additional works at: https://knowledgecommons.popcouncil.org/departments_sbsr-pgy

Part of the Education Policy Commons, Family, Life Course, and Society Commons, and the Gender Equity in Education Commons

How does access to this work benefit you? Let us know!

\section{Recommended Citation}

International Institute for Population Sciences (IIPS) and Population Council. 2010. "Ensuring education for all in India: Highlighting the obstacles," Youth in India: Situation and Needs Policy Brief no. 31.

Mumbai: IIPS. 


\section{Ensuring education for all in India: Highlighting the obstacles}

The extent to which India will be able to successfully harness its demographic dividend depends significantly on the situation of its youth, notably on the levels of education and market-oriented skills they attain. On average, youth in the country have attained 8-9 years of schooling. Yet it is not clear that youth, particularly young women are prepared for the challenges they will face in a globalised world. For example, to what extent are gender gaps in educational attainment narrowing, and are opportunities available to youth that enable them to complete secondary education, increasingly a pre-requisite to participation in the labour market in the context of globalisation? ${ }^{\mathrm{ab}}$

Looking at the current educational situation of youth in India, this policy brief argues that significant investments in terms of appropriate policies and programmes are required to enable the country to achieve the Millennium Development Goals of universal primary education and elimination of gender disparity in primary and secondary education, harness its demographic dividend and enable its youth to participate in and benefit from global development.

\section{The study}

Data are drawn from the Youth in India: Situation and Needs study, a sub-nationally representative study undertaken for the first time in India of key transitions experienced by young people in six states of India, namely, Andhra Pradesh, Bihar, Jharkhand, Maharashtra, Rajasthan and Tamil Nadu. These states were purposively selected to represent the different geographic and socio-cultural regions within the country, and these six states together represent two-fifths of the country's population. The study included a representative survey of young people in both rural and urban settings. Respondents included unmarried women and men and married women aged 15-24 and, in view of the paucity of married men in these ages, married men aged 15-29.
The surveys in the six states were undertaken in a phased manner and took place between January 2006 and April 2008. A total of 50,848 married and unmarried young men and women were interviewed in the survey. These included 8,052 married young men, 11,522 unmarried young men, 13,912 married young women and 17,362 unmarried young women. This brief is based on data obtained from 14,281 men and 31,274 women aged 15-24.

\section{School enrolment is far from universal for young women}

Findings from the Youth Study indicate that while over $90 \%$ of young men had been to school, schooling was far from universal among young women in the country; indeed, one in four young women $(25 \%)$ had never been to school. Even among the younger cohort (aged 15-19), 22\% of young women had never been to school. Married young women and those in rural areas were, moreover, far more disadvantaged than the unmarried and those in urban areas. Almost two-fifths of married young women $(38 \%)$ had never been to school, compared to one-tenth of unmarried young women. Likewise, onethird of young women in rural areas (32\%) compared to one-tenth of those from urban settings (9\%) had never been to school.

State-wise differences were also apparent: $10-16 \%$ of young men and $38-51 \%$ of young women from the northern states of Bihar, Jharkhand and Rajasthan had never been to school, compared to $2-8 \%$ and $5-21 \%$, respectively, in Maharashtra and the southern states of Andhra Pradesh and Tamil Nadu.

Wide gender differences remain in the achievement of educational milestones

Although such milestones as Classes 4, 7 and 10 were not universally achieved by either young men or young women, the female disadvantage in educational attainment was pronounced. About three-quarters of young women $(71 \%)$ had completed Class 4 and

Percentage of youth who had never been to school, according to selected characteristics and state

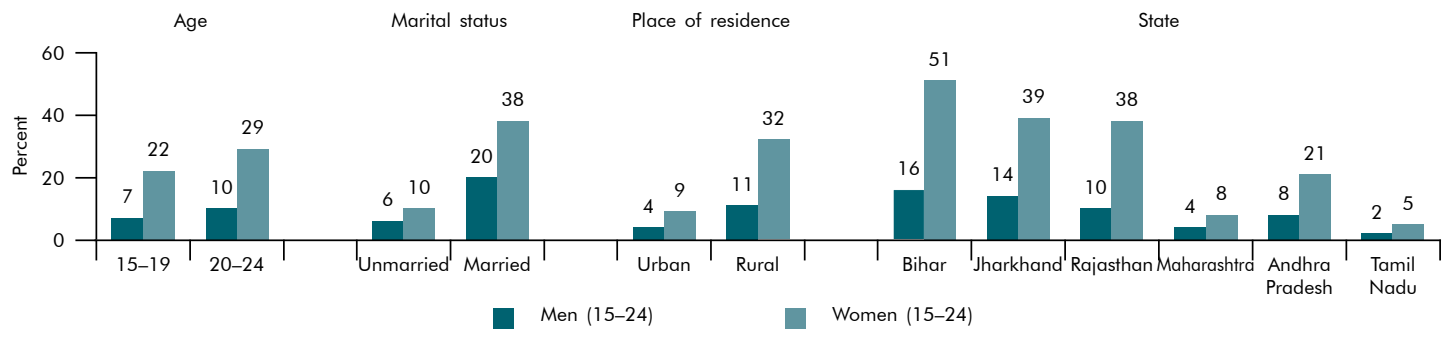

a United Nations. 2007. Goals and targets for monitoring the progress of youth in the global economy: Report of the Secretary-General. New York: United Nations.

b National Research Council and Institute of Medicine. 2005. Growing up Global: The Changing transitions to Adulthood in Developing Countries. Washington, D.C.: The National Academy Press. 
Percentage of youth who had completed Classes 4, 7 and 10

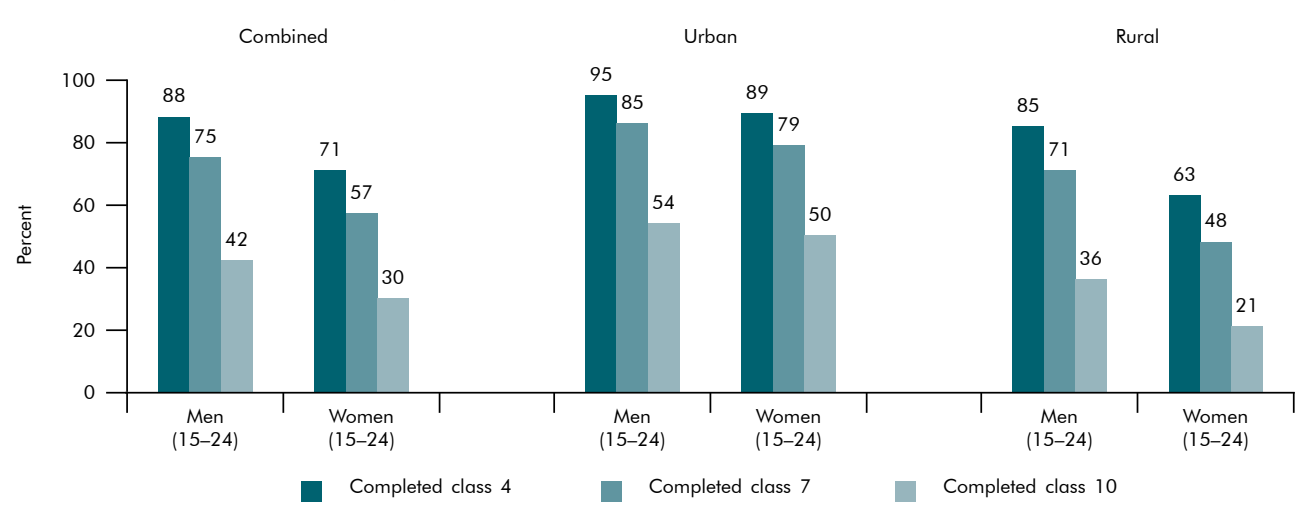

Percentage of youth who had completed secondary school, according to household economic status

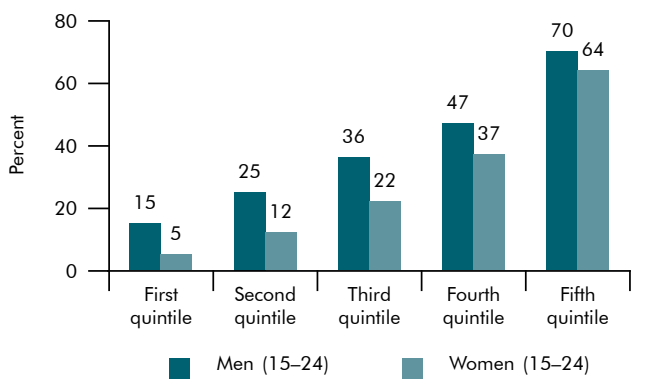

about three-fifths (57\%) had completed Class 7. In contrast, $88 \%$ and $75 \%$ of young men had completed Classes 4 and 7, respectively. Rural youth, particularly rural young women, were far more disadvantaged than their urban counterparts in terms of completion of Classes 4 and 7. Among rural young women, just over three-fifths $(63 \%)$ had completed Class 4 and about half $(48 \%)$ had completed Class 7 , compared to $89 \%$ and $79 \%$, respectively, among young women in urban areas.

Just two in five young men $(42 \%)$ and fewer than one in three young women $(30 \%)$ had completed 10 or more years of education. Indeed, even among those aged 18 and above, only $46 \%$ of young men and 32\% of young women had completed secondary school.

Of note is the striking difference in the proportion of young people who had completed 10 or more years of education by economic status of young people's households, as measured by wealth quintiles (with the first quintile representing households of the lowest wealth status and the fifth quintile representing households of the highest wealth status). Differences by economic status were much wider than either

Percentage of youth who had completed secondary school, according to state

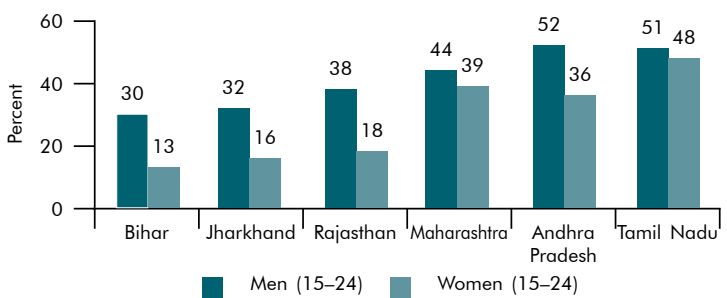

gender differences or differences by rural-urban residence. For example, among young men, just 15\% of those from households in the poorest quintile had completed 10 or more years of schooling, compared to $70 \%$ of those from households in the wealthiest quintile. Among young women, just 5\% of those in the poorest quintile, compared to $64 \%$ of those in the wealthiest quintile, had completed 10 or more years of education.

Also notable are state-wise differences; far larger proportions of youth in Maharashtra and the southern states compared to those from the northern states, had completed 10 or more years of education. Among young men, $44-52 \%$ of those from Maharashtra and the southern states had completed 10 or more years of education, compared to $30-38 \%$ of those from the northern states. Among young women, 36-48\% of those in Maharashtra and the southern states, compared to $13-18 \%$ of those in the northern states had done so.

The leading obstacles that inhibit youth from reaching educational milestones

Poverty's grip keeps young people out of school Leading among factors that inhibited school enrolment and completion were economic reasons (work on the family farm or business, wage earning work and family poverty, ie., the family could not afford to keep the respondent in school) and among young women, a related factor, namely domestic responsibilities as well. Indeed, among young men, economic factors were the most commonly cited reason for never being enrolled in school, as well as for discontinuing schooling at each level of education. For example, three-fifths of young men who had never been to school reported economic reasons, as did almost two-thirds each (64-65\%) of those who discontinued before completing Classes 7 and 10. Young women were less likely to report economic reasons, and it is notable that as progressively higher milestones were attained, economic reasons became progressively less prominent among them: For example, while $56 \%$ of young women who had never been to school reported that they were not enrolled for economic reasons, this percentage fell to $41 \%$ and $33 \%$, respectively, among those who discontinued their education before completing Classes 7 and 10 .

Domestic responsibilities were cited, as expected, by more young women than men. Half of young women $(52 \%)$ compared to one-quarter of young

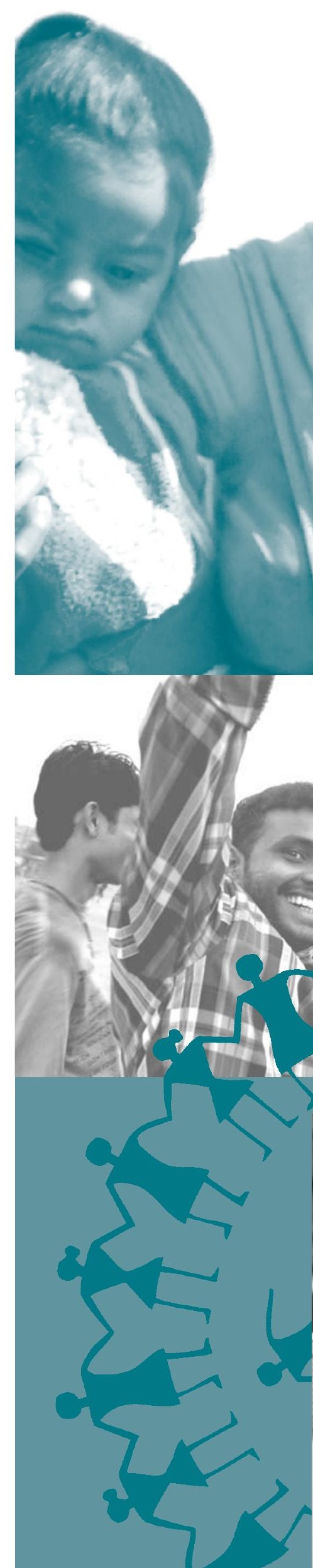


Of those who had never enrolled/discontinued schooling, percentage of youth who cited economic constraint, and the burden of domestic responsibilities

Economic reasons

Domestic responsibilities

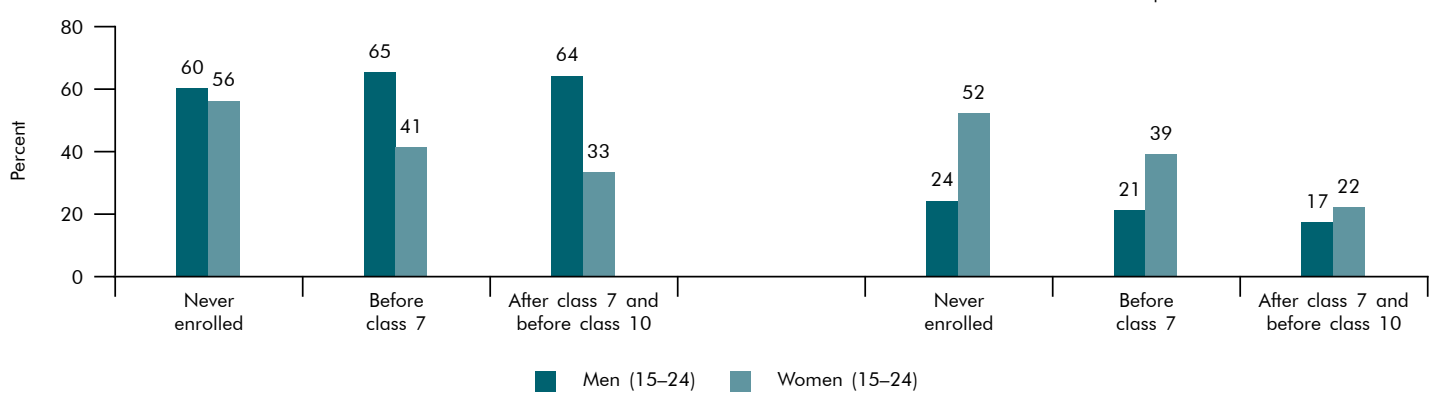

men $(24 \%)$ who had never been to school cited domestic responsibilities as the reason. Domestic reasons became progressively less prominent obstacles to schooling as progressively higher milestones were attained: they were cited by two-fifths of young women $(39 \%)$ and one-fifth of young men (21\%) who had discontinued schooling before completing Class 7 , and by even fewer $(22 \%$ and $17 \%$, respectively) of those who discontinued their education between Classes 7 and 10 .

Unfavourable attitudes to education deter many Unfavourable attitudes and perceptions of youth and their parents regarding education (for example, that education was unnecessary or the respondent was not interested in schooling) were also a key factor that inhibited many youth from getting enrolled in the first place or continuing schooling. Almost two in five young men $(37 \%)$ who had never enrolled in school cited attitude and perception-related reasons, so did $39-45 \%$ each of those who discontinued their education before completing Classes 7 and 10. Among young women, between one-third and two-fifths (34-38\%) each of those who had never been to school as well those who discontinued their education in Classes 7 and 10 reported these reasons.

School-related issues are significant, particularly for young women

Although school-related issues were infrequently cited as the reason for never attending school, one in twelve young men and almost one in five young women so reported. School related reasons became more important factors accounting for discontinuation among youth who discontinued their education before completing Classes 7 and 10, respectively. For example, $26 \%$ of young women who discontinued their education before completing Class 7 and $47 \%$ of those who discontinued their education after completing Class 7 and before completing Class 10 reported that such school related factors as distance and failure to pass their school examination had prevented them from continuing in school. Although fewer young men reported school related obstacles as reasons for school discontinuation, among them too, school related reasons became more important reasons for school discontinuation among those who discontinued their education before completing Classes $7(16 \%)$ and 10 $(36 \%)$, respectively.

\section{Pressure to marry early adds to young women's disadvantage}

Many young women but hardly any young men reported that marriage had interrupted their schooling. Indeed, almost one quarter of married
Of those who had never enrolled/discontinued schooling, percentage of youth who cited unfavourable attitudes regarding schooling

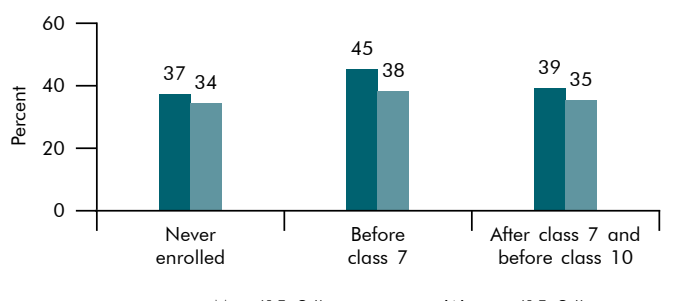

young women who had discontinued their education before completing Class 10 reported reasons related to transitions to adult roles, namely, marriage.

Availability of basic amenities in schools Findings suggest that irrespective of the level of education that youth have reached, the schools attended by many youth lacked basic amenities. Although drinking water was available in most schools, toilet facilities, so essential for girls in particular, were not available to many - as many as $27 \%$ of young men and $17 \%$ of young women who were studying in Classes 8-10 at the time of the interview, for example, did not have access to a toilet. Library facilities were less likely to be available: Just $49 \%$ of young men and $59 \%$ of young women who were studying in Classes 8-10 at the time of the interview reported that library facilities were available, for example.

Moreover, differences were observed in the availability of amenities at educational facilities attended by youth who were still in school and those who had discontinued their education at various levels. Indeed, youth who were still studying were somewhat more likely to report the availability of all four amenities-water, toilets, playgrounds and libraries - than were those who had discontinued their education: for example, among those at higher secondary or college level at the time of the interview, $70-77 \%$ reported access to all four amenities, compared with $62-65 \%$ among those who had discontinued their education at these levels.

Findings also show that considerable proportions of youth required private coaching - almost half of young men $(46 \%)$ and two-fifths of young women $(41 \%)$ who were studying in Classes $8-10$ at the time of the interview. 
Of those who had never enrolled/discontinued schooling, percentage of youth who cited school-related barriers

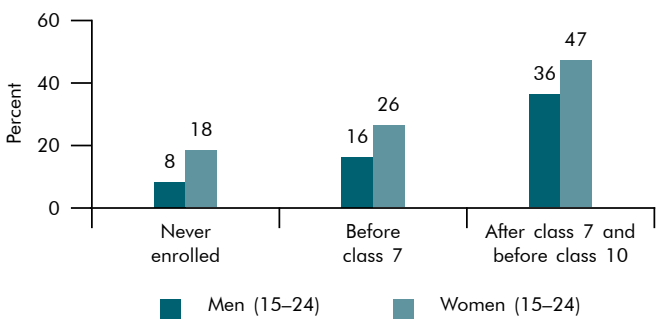

Programme recommendations

India has made many policy and programme commitments to ensure universal access to primary and secondary education. It is committed, for example, to achieve Millennium Development Goals of universal primary education and eliminating gender disparity in primary and secondary education by the year 2015 . The recently enacted Right of Children to Free and Compulsory Education Act 2009, moreover, has made education compulsory for all children up to the age of 14. Moreover, several central and state government programmes are ongoing, including the Sarva Shiksha Abhiyan, the Rashtriya Madhyamik Shiksha Abhiyan, and the Saakshar Bharat scheme, that are intended to encourage school enrolment and retention. What is required now are that policy commitments are met and programmes are effectively implemented. While the achievement of universal school enrolment and primary school completion are key goals, the importance of high school education in enabling youth to make a successful transition to adulthood underscores the need, at the same time, for efforts to overcome barriers to high school completion.

\section{Address economic pressures}

Efforts must be made to address the economic pressures that dissuade parents from enrolling their children in school and from keeping them in school once enrolled. A number of centrally- and state-sponsored programmes are ongoing that aim to reduce the cost of education, and it is important to ensure that these ongoing government programmes do indeed reach the most disadvantaged groups. At the same time, additional inputs, by way of conditional grants that encourage school completion among disadvantaged groups, also need to be considered.

\section{Raise aspirations of youth and parents regarding} education

Activities directed at parents are needed that promote positive attitudes towards education and school completion, raise their aspirations about their children's education and encourage greater parental involvement in their children's education. There is also a need to incorporate livelihood skills building models within the school setting and provide opportunities for those in school to gain market-driven job skills that will raise the aspirations of youth regarding their education and career.

\section{Address school-related barriers}

The Sarva Shiksha Abhiyan has gone a long way in improving access to schools and infrastructure and amenities available in schools. Yet, as seen above, challenges remain. Activities must address school-related barriers, notably, poor infrastructure, quality of education and academic failure, particularly among young women. Attention must be paid to ensure that schools, particularly at primary level, are accessible to all youth and that basic amenities are available in all schools. In addition to the Sarva Shiksha Abhiyan, several state governments have launched various schemes to address these school-related barriers (for example, the bicycle schemes for girls in Jharkhand and Bihar); it is important that the effectiveness of these schemes is evaluated, promising lessons assimilated and the schemes scaled up. Given the large proportions reporting that schooling had been interrupted because they were required for work on the family farm or business or for housework, and given the reality of young people's lives and the economic pressures on families, efforts need to be made to adjust school timings, including the establishment of evening schools to enable children to accommodate work on the family farm or business without sacrificing their education. Finally, there is also a need to focus on providing better training to teachers and ensuring their accountability-investments that are likely to improve the quality of the schooling experience for youth.

\section{Eliminate the practice of early marriage}

Findings indicating that transition to adult roles, particularly early marriage, was an important reason for school discontinuation among young women who discontinued their education before completing Classes 7-9 and Classes 10-11, respectively, emphasise the fact that programme commitments outside the education sector are also critical to the achievement of universal school completion. Specifically required are programmes that seek to critically examine norms and practices surrounding marriage and to eliminate the practice of early marriage. Explorations of subsidies and cash transfers that link school retention with delayed marriage among girls are needed.

Provide a second chance to obtain a basic education to youth left behind

Findings that several sub-groups of youth-young women, the married, the rural, those belonging to poor households, Muslim youth and those belonging to scheduled castes and tribes-remain considerably disadvantaged call for efforts that specifically target these vulnerable groups. Interventions are needed that give youth who missed the opportunity to obtain adequate formal education a second chance to acquire equivalency to formal education.

\section{Implement state-specific programmes to address barriers} to school enrolment and completion

Findings indicating considerable state-wise differences in school enrolment and completion call for state-specific interventions. Targeted efforts to achieve universal school enrolment and at least primary school completion need to be a high priority in the northern states, while concerted efforts to achieve universal secondary school completion are called for in Maharashtra and the southern states. At the same time, efforts to provide a second chance to youth who missed the opportunity to acquire an adequate level of formal education are called for in all the six states.
Suggested citation: International Institute for Population Sciences (IIPS) and Population Council. 2010. Ensuring education for all in India: Highlighting the obstacles, Youth in India: Situation and Needs 2006-2007, Policy Brief No. 31. Mumbai: IIPS. 